\title{
Prenatal testing for Huntington's disease: a European collaborative study
}

\author{
Sheila A Simpson ${ }^{\star, 1}$, Moniek W Zoeteweij ${ }^{2}$, Kurt Nys $^{3}$, Peter Harper ${ }^{4}$, Alexandra Dürr ${ }^{5}$, Gioia
} Jacopini $^{6}$, Christos Yapijakis ${ }^{7}$ and Gerry Evers-Kiebooms ${ }^{3}$

${ }^{1}$ Clinical Genetics: ForesterHill, Aberdeen, UK; ${ }^{2}$ Center of Human and Clinical Genetics: Wassenaarseweg 72 , Leiden, The Netherlands; ${ }^{3}$ Center for Human Genetics: Herestraat 49, Leuven, Belgium; ${ }^{4}$ Institute of Medical Genetics: Heath Park, Cardiff, UK; ${ }^{5}$ Departement de Génétique, Cytogénétique et Embryologie: Hôpital de la Sal Petriere, Paris, France; ${ }^{6}$ Istituto di Psicologia: Viale Marx 15, Rome, Italy; ${ }^{7}$ Department of Neurology: Egnition Hospital, Athens, Greece

This European study involving seven genetic centres from six countries - Aberdeen, Cardiff (UK), Leiden (Netherlands), Leuven (Belgium), Paris (France), Rome (Italy), Athens (Greece) has gathered information on prenatal testing by direct mutation analysis and exclusion testing for Huntington's disease (HD) from the six European countries during the period 1993-1998. Data describing the parent belonging to the HD family was collected; this included their sex and age as well as their risk of developing HD.

Information about previous pregnancies, the rank of the pregnancy being tested and its outcome was also gathered. In addition the number of previous prenatal tests for HD was recorded. Three hundred and five results were recorded by the participating countries between 1993 and 1998. The largest groups came from the UK (157) and the Netherlands (90). The mean age for the parent from the HD family was 30.8 years. In half of the tests the prospective parent was an asymptomatic gene carrier, $42 \%$ remained at risk, and $6 \%$ of the prospective parents were already showing clinical features of HD. $65 \%$ of tests performed used mutation analysis.

European Journal of Human Genetics (2002) 10, 689-693. doi:10.1038/sj.ejhg.5200871

Keywords: Huntington's disease; prenatal testing; demographic variables

\section{Introduction}

Huntington's disease (HD) is an autosomal dominant, adult onset, neurodegenerative disease for which there is no cure. Clinical features include an involuntary, usually choreiform movement disorder, cognitive decline, personality change and psychiatric disease. Mean age of onset is 40 years but this is variable, and symptoms can be present for 20 years before death. ${ }^{1}$

The mutation responsible for HD is an expanded trinucleotide (CAG) repeat in the huntingtin gene on chromosome $4 .^{2}$ Presymptomatic predictive testing and

*Correspondence: Dr SA Simpson; Medical Genetics, Medical School, Grampian University Hospitals, Foresterhill, Aberdeen, AB25 2ZD, UK. Tel: 44 1224552120; Fax: 441224559390 ;

E-mail: s.a.simpson@abdn.ac.uk

Received 5 February 2002; revised 8 July 2002; accepted 10 July 2002 prenatal testing have been possible since 1993 by direct mutation analysis. Using linkage analysis it is also possible to perform exclusion testing so that the chromosome 4 at $50 \%$ risk can be identified as present in the foetus or not. This allows an individual to have children who will not have inherited the disease, even if the parent does not wish their own status to be defined. Using this method means that pregnancies that are not at risk may be terminated.

Given the technical feasibility of prenatal testing in HD, and the severity of the disorder, it might be expected that prenatal diagnosis would be frequently requested. However, many couples express their anxiety about having any children at all, since they do not wish any child of theirs to grow up with an affected parent, even if it were known that the child would not be at risk because of antenatal testing. These individuals may have grown up in a family where 
alcoholism, suicide, and marital discord - including divorce - are common. ${ }^{1}$

Tyler $^{3}$ reviewed a group of referrals for exclusion testing in pregnancy in the period 1986-1989. The authors surveyed a group of individuals at $50 \%$ risk of developing HD about their attitudes to prenatal testing. Fifteen out of a total of 90 couples referred for exclusion testing underwent testing in 24 pregnancies. They concluded that the demand for such testing was likely to be small. The most common reason for not proceeding with testing was dislike of termination of pregnancy. The authors emphasised the need for intensive counselling, since many couples were uncertain about how the test worked.

Adam $^{4}$ also reported fewer individuals using prenatal diagnosis than had been their original intention. Fortythree per cent of this Canadian group who entered the presymptomatic predictive test programme stated that they would use prenatal testing. In the period of the study, $18 \%$ of those with unfavourable results, who had had a pregnancy, used prenatal testing. In a survey of individuals from Germany who were at risk of $\mathrm{HD},{ }^{5}$ over $67 \%$ indicated that they would wish to undergo presymptomatic predictive testing themselves, but only $45 \%$ would wish to use prenatal diagnosis. Twenty-seven per cent of those questioned stated they could not use prenatal diagnosis because they felt they could not terminate a pregnancy.

A minority of those at risk of Huntington's disease in the UK has chosen to prevent the transmission of the disease by the use of prenatal diagnosis. ${ }^{5}$ A larger number have undertaken predictive testing. ${ }^{6,7}$

Despite the low uptake of prenatal testing, there is data $^{8-13}$ from many centres describing individuals who undergo presymptomatic predictive testing for HD which gives family planning as a major reason for undergoing such a test.

This paper describes the data gathered as part of a European Commission funded project (BIOMED project No ERB BMH4-CT98-3926) concerning those who undertake prenatal testing in Huntington's disease, and how often. These data were gathered as part of a multidisciplinary study into the psychosocial, ethical and legal complexities of prenatal testing for this late onset disease. Another part of the European collaborative study describes the reproductive choices of those who undertook predictive testing. ${ }^{10}$

\section{Methods}

Collaborators from seven genetic centres in six European countries - Aberdeen and Cardiff (UK), Leiden (Netherlands), Leuven (Belgium), Paris (France), Rome (Italy), Athens (Greece), gathered information on all prenatal tests for HD by direct mutation analysis and exclusion testing during the period 1993-1998 in the six countries.

Information about the date of the test, sex of parent at risk, the status of the prospective parent, the age, education and marital status of the prospective parents, the rank of the pregnancy, information about previous pregnancies, and the type and result of the prenatal test was requested. Since the data were collected for each test performed, information about the characteristics of the couple is included more than once if that couple had more than one prenatal test.

All questionnaires were completed by the clinicians (mainly clinical geneticists or psychologists) that dealt with the families, and these were sent to the co-ordinating centre in Leuven where the data were analysed. All data were anonymised before being sent to the co-ordinating centre, to ensure confidentiality.

\section{Results}

Description of prenatal tests for the period 1993-1998

A total of 305 prenatal tests were performed (Table 1) in the six countries between 1993 and 1998. In Italy two of the tests were initially performed using exclusion testing, but when the risk of $50 \%$ was produced for the foetus, direct testing was undertaken.

The mean age of the prospective parent was 30.8 years, with a range of $17-41$ years $(n=167) .53 .9 \%$ of the prospective parents were female $(n=191)$ (Table 2$)$. The mean age of the partner (where this was available) was 31.5, and the range was 20-42 years $(n=133)$. Forty-eight per cent of all tests were performed in the context of a stable relationship. The status of another $48 \%$ of the relationships was unknown and $4 \%$ of the tests were performed in women

Table 1 Number and type of prenatal tests in the six participating countries in the period 1993-1998

\begin{tabular}{lllll}
\hline Country & $\begin{array}{l}\text { Population } \\
\text { (million) }\end{array}$ & $\begin{array}{l}\text { Direct } \\
\text { testing }\end{array}$ & $\begin{array}{l}\text { Exclusion } \\
\text { testing }\end{array}$ & Total \\
\hline Belgium & 10.3 & 27 & 3 & 30 \\
France & 59.5 & 5 & 2 & 7 \\
Greece & 10.6 & 2 & 0 & 2 \\
Italy* $^{*}$ & 57.6 & 11 & $8(2)$ & 19 \\
Netherlands & 15.9 & 73 & 17 & 90 \\
UK & 59.6 & 81 & 76 & 157 \\
Total & & 199 & 106 & 305 \\
\hline
\end{tabular}

${ }^{*}$ In Italy two of the tests were initially performed using exclusion testing, but when the risk of $50 \%$ was produced for the foetus, direct testing was undertaken.

Table 2 Sex of prospective parent in the six participating countries (114 cases missing)

\begin{tabular}{lcc}
\hline Country & Mother & Father \\
\hline Belgium & 16 & 14 \\
Netherlands & 54 & 36 \\
UK & 20 & 23 \\
France & 4 & 3 \\
Italy & 8 & 11 \\
Greece & 1 & 1 \\
Total & 103 & 88 \\
\hline
\end{tabular}


who were not in a stable relationship. The educational status of the couple was often unreported, and therefore it is not discussed further in this paper.

In $51 \%$ of the cases, the prospective parent was an asymptomatic carrier of the mutation for $\mathrm{HD}$, in $42 \%$ the parent remained at risk, and in $6 \%$ the parent showed clinical features of HD. In $1 \%$ of cases the parent had an intermediate allele (Table 3).

In the six countries, $65 \%$ of prenatal tests were performed by mutation analysis, and in $78 \%$ of these cases, the prospective parent was known to have the mutation, but was asymptomatic. Eight per cent of the prenatal tests by mutation analysis were performed in couples where the parent belonging to the HD family was symptomatic of HD. Two per cent of the tests involved an intermediate allele, and interestingly, $12 \%$ of the tests were performed in those who were still at risk, that is their status had not been defined. The majority of those who remained at risk for $\mathrm{HD}$ chose to undergo exclusion testing (Table 4).

In $43 \%$ (131) of the total cases the result was unfavourable. Eight of these pregnancies were continued. Six of these eight prenatal results were produced by direct mutation analysis, and therefore a presymptomatic predictive test result is available for these children.

\section{Discussion}

The data presented have been gathered from six countries. It was not always possible to gather complete information about total numbers of tests for each country as a few centres in those six countries did not participate in the study; Greece, the Netherlands and the UK are the exceptions to this.

Table 3 Status of prospective parent in the six participating countries (two cases missing)

\begin{tabular}{lcccr}
\hline & Affected & $\begin{array}{c}\text { Asymptomatic } \\
\text { carrier }\end{array}$ & $\begin{array}{c}\text { Intermediate } \\
\text { allele }\end{array}$ & At risk \\
\hline Belgium & 0 & 25 & 1 & 4 \\
Netherlands & 0 & 64 & 1 & 25 \\
UK & 16 & 52 & 0 & 87 \\
France & 0 & 5 & 0 & 2 \\
Italy & 0 & 8 & 1 & 10 \\
Greece & 1 & 0 & 0 & 1 \\
Total & 17 & 154 & 2 & 129 \\
\hline
\end{tabular}

Table 4 Type of test and status of prospective parent in the six participating countries (two cases missing)

\begin{tabular}{lcc}
\hline Status & Mutation analysis & Exclusion testing \\
\hline Affected & 17 & 0 \\
Asymptomatic gene carrier & 154 & 0 \\
Intermediate allele & 3 & 0 \\
At risk & 24 & 105 \\
Total & $198(65 \%)$ & 105 \\
\hline
\end{tabular}

When we compare the uptake for prenatal testing for HD in the six European countries described, the data show clearly that less prenatal tests for HD were performed in France, and almost none in Greece, in the period 19931998. These centres also have fewer predictive tests than others in the study. There is no data to explain this phenomenon.

Other centres have reported their experience of prenatal testing in those at risk of HD. Simpson ${ }^{5}$ noted that despite earlier work that had suggested that uptake would be greater, the number of prenatal tests in the UK was low compared with presymptomatic predictive tests. A total of $2937^{7}$ predictive tests have been performed in the UK up to the end of 1997, 2502 based on specific mutation testing, feasible since 1993. Almost all presymptomatic and prenatal tests are carried out in National Health Service genetics centres, using a defined genetic counselling protocol and with availability now in all regions of the UK. As a result, the data are believed to be very accurate. The trend in test numbers has currently levelled out at around 500 per year. In contrast, 146 antenatal tests were performed in the 5 years 1994-1998, with a range of $15-37$ each year. ${ }^{5}$

Maat-Kievit ${ }^{14}$ described the experience in the Netherlands in prenatal testing in HD from 1987-1997 (although the first test was requested in 1989). This paper also describes a low uptake of prenatal testing for HD, 2\% of at risk individuals, and $11 \%$ of carriers of the mutation chose prenatal testing in the period described. In addition, in $3 \%$ of the cases, mutation analysis was used in pregnancies where the status of the parent had not yet been defined. Forty-three per cent of the total tests were by exclusion testing, although use of this method had decreased in proportion to mutation analysis since the discovery of the mutation for HD in 1993.

Based on the data produced by the seven genetic centres participating in this European collaborative study, an estimation of the ratio (number of prenatal tests)/(number of predictive tests) until the end of 1998 has been made. It revealed that the number of prenatal tests was less than $10 \%$ of the number of predictive tests in a comparable period.

The low uptake of prenatal testing in those who are known to carry the mutation, may be partly explained by the fact that many people who undergo predictive testing for $\mathrm{HD}$ are in their thirties, and already have at least one child. They may have completed their families, or choose not to have further children who then would have different risks of developing the disease.

Exclusion testing remains a valuable tool for couples who do not wish to define their own risk, but none the less wish to have children who will not develop Huntington's disease. In this series, $34.8 \%$ of the tests were exclusion tests. Data is not available to discuss this, although personal communication (Simpson, 2002) would suggest that there 
is a group of those at risk for HD who could not tolerate knowing their own status, but are committed to having children who will not develop the disease.

In some cases, couples at risk chose to have their pregnancies investigated by mutation analysis, even though the prospective parent remained at risk at the time of the test. The available data did not allow further analysis of this phenomenon, though the centres concerned all used recognised guidelines for testing, ${ }^{15}$ and the couples were all fully informed about the possible consequences of such a decision. One reason for taking such an action is that individuals do not wish to terminate a pregnancy which may not be at risk, and therefore chose not to use exclusion testing, preferring instead to take the chance of finding out their own status during antenatal testing.

The trauma associated with termination of any pregnancy is considerable. Tolmie described a group of UK families who had difficulty with their decision to terminate an at risk pregnancy following exclusion testing. ${ }^{16}$ Three out of nine high-risk pregnancies were continued. Clarke ${ }^{17}$ demonstrated the problems associated with cases where an unfavourable result is produced, but the pregnancy continues. Children will grow up knowing their status, having been denied making that choice for themselves. In addition the prejudices of their parents and those of society can be expected to be disadvantageous for them.

In common with other reports, ${ }^{5,14}$ this study has shown a greater number of women at risk who choose prenatal testing. This has not been investigated in this study, but it has been suggested ${ }^{14}$ that men are less likely to make this decision since they do not wish to burden their wives who have to undergo the tests themselves. Women may also be more involved in reproductive decision making than their partners. ${ }^{6}$

Few other options are available to the couples who wish to have children but do not wish to have prenatal testing. For example, egg or sperm donation is available in some centres, although some couples have denied use of this method because of their risk of developing HD (Simpson, personal communication). Couples who have attempted to adopt or foster have also had considerable difficulties because of the at risk status of one of the partners. ${ }^{18,19}$

It is now becoming possible to offer preimplantation diagnosis to couples who do not wish investigation of an established pregnancy. This technique is offered at only a few centres in the world, and is not easily available to most couples. Moreover, the baby take home rate remains low. ${ }^{20-24}$ There are no data from these techniques in this study, which focussed on prenatal testing during the first trimester of pregnancy.

This European study confirmed that the number of presymptomatic predictive tests for HD far exceeds that for prenatal testing. None the less, for those who use prenatal testing, it is clearly an important tool, and they are committed to it.
There has been debate about whether it is ethical to use prenatal testing in $\mathrm{HD}^{25}$ In the countries and centres described in this paper, genetic counselling and psychological support is provided to couples who are first fully informed about the nature and consequences of the testing procedure before they take this important decision. Despite a comparatively low uptake of the procedure, it remains important to offer choice and support to couples who are at risk of HD, and wish to have children.

\section{Acknowledgements}

Very special gratitude is expressed to the many persons in the participating countries and to their colleagues from other genetic centres in their country, without whom the present study would have been impossible. The authors of this paper acknowledge the contribution of authors in the following countries In Belgium: Dr M Decruyenaere, Mrs $T$ Cloostermans, Mrs A Boogaerts, Prof J-P Fryns (Center for Human Genetics, Leuven); Prof J Dumon (Dienst voor erfelijkheidsonderzoek en advies, Antwerpen); Prof Y Gillerot (Departement de Genetique Medicale, Loverval); Prof A De Paepe, Mrs Isabelle Delvaux (Dienst Medische Genetica, Gent); Prof I Liebaers (Dienst Medische Genetica, Brussels); Prof M Abramovicz (Centre de Genetique, Bruxelles); Prof A Verloes (Service de Genetique Humaine, Liege); Prof C Verellen (Centre de Genetique Medicale, Bruxelles). In France: Prof Josue Feingold, Marcela Garguilo, Tecla Capecchi, Dr Khadija Lahlou (Hopital de la Salpetriere). In Greece: Prof C Papageorgiou, Prof M Dalakas, Prof D Vassilopoulos, Dr C Voumvourakis, Dr M Panas, Mrs $S$ Pomoni (Department of Neurology, University of Athens); Prof D Loukopoulos, Mrs K Palioniko (1st Department of Internal Medicine, University of Athens); Prof C Metaxotou, Dr S Youroukos (1st Department of Pediatrics, University of Athens); Assoc Prof A Antsaklis (1st Department of Gynecology and Obstetrics, University of Athens); Prof A Plaitakis, Dr M Tzagournissakis (Department of Neurology, University of Crete, Herakleion). In Italy: Dr M Frontali (Istituto di Medicina Sperimentale C.N.R., Rome); Prof B Brambati (Istituto Ostetrico Ginecologico L.Mangiagalli, Milan); Prof P Mandich (Dipartimento di Biologia, Oncologia e Genetica, Genoa); Prof A Renieri (Istituto di Genetica Medica, Università di Siena); Dr M Genuardi (Istituto di Genetica Medica, Università Cattolica Sacro Cuore, Rome); Prof G Novelli (Cattedra di Genetica Medica, Università Tor Vergata, Rome); Dr M Ferrari (Sezione Biologia Molecolare Clinica, Ospedale San Raffaele, Milan); Prof E Calzolari (Cattedra Genetica Umana, Università di Ferrara). In The Netherlands: JA Maat-Kievit, Prof Dr MH Breuning (Center of Human and Clinical Genetics Leiden); Dr M Losekoot, Prof Dr B Bakker (DNA-diagnostic laboratory, Center of Human and Clinical Genetics Leiden); MN Ane, Section of Neuropsychology, Dept of Neurology, Leiden; Dutch working group on Huntington's Disease, a collaboration between Afdeling Erfelijkhieidsadvisering Academisch Medisch Centrum Amsterdam (Prof Dr NJ Leschot); Afdeling Klinische Genetica Vrije Universiteit Amsterdam (Prof Dr LP ten Cate); Afdeling Erfelijkheidsvoorlichting Rijksuniversiteit Groningen (Dr JAvan Essen); Afdeling Erfelijkheidsvoorlichting Stichting Klinische Genetica ZO Nederland Maastricht (Dr C Schrander-Stumpel); Afdeling Klinische Genetica Radbout Ziekenhuis Nijmegen (Prof Dr H Brunner); Afdeling Klinische Genetica Erasmus Universiteit Rotterdam (Prof Dr H Galjaard); Divisie Medische Genetica Universitair Medisch Centrum Utrecht (Prof Dr $D$ Lindhout); Centrum voor Humane en Klinische Genetica Leids Universitair Medisch Centrum Leiden (Prof Dr MH Breuning). In 
the UK: Mrs $R$ Glew, Dr $R$ Harper (Institute of Medical Genetics, Cardiff); The members of the UK Huntington's Disease Prediction Consortium.

\section{References}

1 Harper PS: Huntington's Disease. London: Saunders, 1996.

2 Huntington's Disease Collaborative Research Group: A novel gene containing a trinucleotide repeat that is expanded and unstable on Huntington's disease chromosomes. Cell 1993; 72: 971-983.

3 Tyler A, Quarrell O, Lazarou L, Meredith AL, Harper PS: Exclusion testing in pregnancy in Huntington's disease. J Med Genet 1990; 27: $488-495$.

4 Adam S, Wiggins S, Whyte P et al: Five year study of prenatal testing for Huntington's disease: demand, attitudes, and psychological assessment. J Med Genet 1993; 30 (7): 549-556.

5 Simpson SA, Harper PS: Antenatal Testing for Huntington's Disease: Experience within the UK 1994-1998. J Med Genet 2001; 38: 222-225.

6 Crauford D, Dodge A, Kerzin-Storrar L, Harris R: Uptake of presymptomatic predictive testing for Huntington's disease. Lancet 1989; ii: 603-605.

7 Harper P, Lim C, Craufurd D: Ten years of presymptomatic testing for Huntington's disease: the experience of the U.K. Huntington's Disease Prediction Consortium. J Med Genet 2000; 37: 567-571.

8 Kreuz FR: Attitudes of German Persons at risk for Huntington's disease toward predictive and prenatal testing. Genet Couns 1996; 7 (4): 303-311.

9 Evers-Kiebooms G, Decruyenaere M: Predictive testing for Huntington's disease: challenge for persons at risk and for professionals. Patient Education and Counselling 1998; 35: 15-26.

10 Evers-Kiebooms G, Nys K, Harper PS et al: Predictive DNA testing for Huntington's disease and reproductive decision making: a European collaborative study. 2002. Eur J Hum Genet 2002; 10: $167-176$.

11 Kessler S, Field T, Worth L, Mosbarger H: Attitudes of persons at risk for Huntington's disease towards predictive testing. Am J Med Genet 1987; 26: 259-270.

12 Evers-Kiebooms G, Swerts A, Cassiman JJ, Van den Berghe H: The motivation of at risk individuals and their partners in deciding for or against predictive testing for Huntington's disease. Clin Genet 1989; 35: 29-40.
13 Simpson SA, Besson J, Alexander DA, Allan K, Johnston AW: One hundred requests for presymptomatic testing in Huntington's disease. Clinical Genetics 1992; 41: 326-330.

14 Maat-Kievit A, Vegter-van der Vlis M, Zoeteweij M, Losekoot M, van Haeringen A, Kanhai H, Roos R: Experience in Prenatal Testing for Huntington's Disease in the Netherlands: Procedures, Results and Guidelines (1987-1997). Prenat Diagn 1999; 18: $450-457$.

15 International Huntington Association, World Federation of Neurology: guidelines for the molecular genetics predictive test in Huntington's disease. Neurology 1994; 44: 1533-1536.

16 Tolmie JL, Davidson HR, May HM, McIntosh K, Paterson JS, Smith B: The prenatal exclusion test for Huntington's disease: experience in the west of Scotland, 1986-1993. J Med Genet 1995; 32 (2): $97-101$

17 Clarke A, Fielding D, Kerzin, Storrar L et al: The genetic testing of children. J Med Genet 1994; 10: $785-797$.

18 Oxtoby M: Genetics in Adoption and Fostering Practice Series 8. British Agencies for Adoption and Fostering, 1982.

19 Mather M, Batty D: Doctors for Children in Public Care. British Agencies for Adoption and Fostering, 2000.

20 Geraedts J, Liebaers I: Preimplantation genetic diagnosis for Huntington's disease; in Evers-Kiebooms G, Zoeteweij M, Harper P (eds): Prenatal testing for late onset neurogenetic diseases. BIOS Scientific Publishers Ltd, Oxford, UK, 2002.

21 Handyside AH: Clinical Evaluation of Preimplantation Diagnosis. Prenat Diag 1998; 1345 - 1348.

22 Sermon K, Goosens V, Seneca S et al: Preimplantation Diagnosis for Huntington's Disease (HD): Clinical Application and Analysis of the HD Expansion in Affected Embryos. Prenat Diagn 1998; 13: $1427-1436$

23 Harper JC, Delhanty JD: Preimplantation genetic diagnosis. Curr Opin Obstet Gynecol 2000; 12 (2): 67-72.

24 Braude PR, de Wert, GM Evers-Kiebooms, G Pettigrew, RA Geraedts, JP: Non disclosure preimplantation genetic diagnosis for Huntington's disease: practical and ethical dilemmas. Prenatal Diagnosis, 1998; 18: 1422-1426.

25 Greenberg J: Huntington disease: prenatal screening for late onset disease. J Med Ethics 1993; 19: 121. 